\title{
Gorkha Earthquake 2015 and Post Disaster Reconstruction in Nepal: Challenges and Prospects
}

\author{
Rajesh Uprety \\ Deputy Superintendent of APF, Nepal \\ Student Officer, $3^{\text {rd }}$ APF Command and Staff Course \\ Email: rajeshuprety2036@gmail.com
}

\begin{abstract}
The Gorkha earthquake of moment magnitude 7.6 hit the central region of Nepal on April 25, 2015; with the epicenter about $77 \mathrm{~km}$ northwest of Kathmandu Valley. This paper aims to explore the challenges and opportunities of reconstruction in earthquake punched areas of Nepal. The Gorkha earthquake on April 25, 2015, has significantly affected the livelihood of people and overall economy in Nepal, causing severe damage and destruction in central Nepal including nation's capital. A larger part of the earthquake affected area is difficult to access with rough terrain and scattered settlements, which posed unique challenges and efforts on a massive scale reconstruction and rehabilitation. Challenge of reconstruction of thousands houses is tough for Nepal in the background of its uproar political scenario and weak governance. With significant actors involved in the reconstruction process, no appreciable relief has reached to the ground, which is reflected over the frustration of affected people. Although the earthquake negatively influenced the country's economy, it opened the opportunity to create sustainable economic developments through proper disaster mainstreaming like construction of earthquake resilience infrastructures, new education and training, media-based mass awareness, and coordinated actions in different parts of the society. Disaster is also an opportunity for development. Hence, if we start thinking for the opportunities after the disaster in a constructive way, still there is a flourishing future of development. This paper is prepared by analyzing few literatures and the personal experiences of the author being as a part of rescue and relief operation in Gorkha during the critical flash of earthquake.
\end{abstract}

Key Words: Gorkha earthquake, disaster, Response, reconstruction

\section{Introduction}

Nepal is exposed to a variety of natural hazards and human induced disasters. More than 80 percent of the total population of Nepal is at risk of natural hazards; such as floods, landslides, windstorms, hailstorms, fires, earthquakes and Glacial Lake Outburst Floods (GLOFs). The country is among the 20 most disaster-prone countries in the world. In part, this is because Nepal is in a seismically active zone with a high probability for a massive earthquake. Globally, Nepal ranks 4th and 11th in terms of its relative vulnerability to climate change and earthquakes, respectively. Out of 21 cities around the world that lie in similar seismic hazard zones, Kathmandu city is at the highest risk in terms of impact on people.

Nepal suffered a massive loss of lives and property on Saturday 25 April 2015, when the devastating earthquake 7.6 magnitude struck Nepal. Subsequent aftershocks, including one of magnitude 7.3 near the Chinese border on 12 May, produced additional losses of life and property. The earthquake triggered avalanches on Mount Everest and in the Langtang valley. Villages were flattened and people were made homeless across 31 districts, with 14 districts (Gorkha, Dhading, Rasuwa, Nuwakot, Kathmandu, Lalitpur, Bhaktapur, Kavrepalanchowk, Sindhupalchowk, Dolakha, Sindhuli, Makawanpur, Ramechhap and Okhaldhunga) suffering the highest impact. Infrastructure was 


\section{7 | Journal of APF Command and Staff College}

damaged throughout the earthquake zone. Historic neighborhoods and heritage sites were destroyed in the Kathmandu Valley.

As a result of the earthquake, 8,896 people died and more than 22,302 people were injured. Assessments showed that affected families 8, 86,456, Displaced Families 6,49,815, Houses Damaged (Fully) 6,04,930, Houses Damaged (Partially) 2,88,856, Total Material and Loss NPRs.706 billion US\$ 7 billion (MoHA, Nepal Disaster report 2015).

The Gorkha Earthquake 2015 will have a long-term effect on Nepal's economy and development efforts for several years. The agriculture, industry, tourism and service sectors have been badly affected. This is a major set-back to Nepal's socio-economic condition. It will take many years to revive.

\section{Response Made}

Nepal's National Disaster Response Framework (NDRF) served as a key tool for coordination of earthquake response, facilitating decisions and instructions from the central to districts. The first meeting of the Central Natural Disaster Relief Committee (CNDRC) was held immediately after the earthquake, with the National Emergency Operation Centre (NEOC) providing an initial report to the CNDRC, recommending a focus on Search and Rescue (SAR), and lifesaving actions. Financial resources from the Prime Minister's Disaster Relief Fund were immediately allocated, and the government's cluster mechanism, comprising 11 clusters, was instantly activated.

Government of Nepal immediately made an official request for international assistance within hours of the earthquake. Several meetings with donor communities were convened to seek international assistance for search and rescue and immediate relief operations. With the limited trained human resource and available equipments, Nepal Army (NA), Nepal Police (NP) and Armed Police Force (APF) carried out effective SAR operations. They were backstopped by dozens of international military Search and Rescue (SAR) teams under the Multi-National Military Coordination Centre. The network of NGOs and INGOs based in Nepal swiftly rallied to support community relief efforts. Several national and international volunteer groups (especially of youth and professionals like doctors and engineers) were voluntarily mobilized in treatment of injured, setting up temporary shelters, and supplying foods and non-food items.

A number of volunteer groups, local people, youths, civil societies, media and political parties provided significant assistance to the affected people during the response. Several International and local NGOs, Red Cross and Red Crescent Societies and United Nations Organizations supported from the beginning of the response. There has also been a considerable amount of aid distributed by various social organizations, private and corporate. This includes skilled technical personnel such as doctors, nurses, engineers as well as unskilled personnel and in-kind contributions. Despite the lack of sufficient search and rescue equipment and resources, security forces played a significant role in search and rescue and relief works.

\section{Reconstruction and Recovery}

The total value of disaster effects (damages and losses) earthquakes is estimated to be about NRs. 706 billion (US\$ 7 billion) that is equivalent to about one third of the Gross Domestic Product (GDP). Out of the total value, the share of destroyed physical assets accounts for NRs. 517 billion (76\% of the total effects). The Post-Disaster Needs Assessment (PDNA) report reveals that the share of the disaster effects across sectors was estimated as: social sector (58\%), productive sector (25\%), infrastructure sector (10\%) and cross-cutting issues (7\%). Similarly, the earthquake had negative 
Uprety: Gorkha Earthquake 2015 and Post Disaster...| 8

impact on production, trade, agriculture, tourism, thereby weakening the national economy. The average economic growth was about $3 \%$ in fiscal year 2014/15, a negative growth rate of -0.77 and recovered to 0.01 in 2015/16 and has picked up slowly and the World Bank has said that Nepal's economic growth has rebounded strongly and has reached 7.5 percent in the fiscal year 2017 .

Post-Disaster Needs Assessment (PDNA) report estimated reconstruction and recovery needs of about NRs. 700 billion would be required to reconstruct the damaged property and infrastructure. However, with government commitment to provide NRs. 3,00,000 instead of NRs 2, 00,000 to each household affected by earthquake increased the reconstruction and recovery needs to about NRs. 900 billion.

National Reconstruction Authority (NRA) has been established in 25 December 2015 (2072) for five years to lead and manage the reconstruction and recovery of the earthquake. The NRA's overall goal is to promptly complete the reconstruction works damage by the earthquake, to promote national Build Back Better interest. NRA has formulated a Post Disaster Recovery Framework (PDRF) (2016-2020) on the basis of PDNA. The government has sufficiently allocated the budget for reconstruction and recovery initiatives. Similarly, almost all of the affected families have received the first installment of the grant and recovery activities have been further expedited.

An international conference on Nepal's reconstruction held in 2015 was able to seek aid of NRs. 400 billion of which about 50\% was grant and 50\% loan. The Prime Minister's Disaster Relief Fund (PMDRF) was created for rescue, treatment, relief, rehabilitation of victims and restoration of physical infrastructure damaged by natural disaster. Money received from other national and international sources was solely aimed at providing relief to the affected people. Nothing worked as planned due to obstacles from multiple factors. In the beginning of local level election 2017, political power struggle, a lack of accountability, poor management of funds, absence of local bodies and regional tensions have all hampered efforts to rebuild. Local level election was held in three phases in 2017. It was thought that the reconstruction bid would be fruitful only after the people's representatives are elected. But, the plight of the people in the quake-ravaged Nepal's reconstruction remains the same.

Obviously, reconstruction is indispensable for revitalizing the national economy. Various research studies findings show that the primary issue is that cash is the most frequently cited priority need. Similarly, it was found that, villages with good road access, higher wealth and family member sending remittance were generally rebuilding faster. Secondly, people have started borrowing mainly from informal sources with increased risk of debt traps. The government, being the top aid provider, could not effectively address the need of the people. If the government could arrange the financial assistance at a reasonable interest rate it would accelerate the reconstruction and recovery process.

\section{Policy, Legal and Institutional Frameworks}

Nepal enacted Natural Calamity (Relief) Act, the first act of this kind, in1982 and established a network of "disaster relief committees" at various levels (Central, Regional, District and Local Disaster Relief Committee) from central to local levels for effective disaster management focusing primarily on response. Now, considering the importance of disaster risk reduction, the Constitution of Nepal has clearly spelled out disaster management functions to be operated in three levels of government structure. Moreover, disaster risk reduction began to receive more attention from Government side since the 10th Five Year development Plan (2002-2007) and the subsequent periodic plans. Furthermore, in alignment with Nepal's commitment to the Hyogo Framework for 


\section{9 | Journal of APF Command and Staff College}

Action (HFA), the Government of Nepal approved the National Strategy for Disaster Risk Management in 2009. This Strategy outlines 29 priority activities for risk reduction and mitigation.

Government of Nepal has also developed new and comprehensive DM Act for an effective DRM effort which would prioritize DRM across government sectors and levels, with a proposed Disaster Management Council chaired by the Prime Minister. Under it, there will be a National Disaster Management Centre as a dedicated institution. After the endorsement of the Disaster Management Bill, it is hoped that, a National Council for Disaster Management chaired by the Prime Minister will be fully functional.

Furthermore, there is a high level Climate Change Council under the chairmanship of the Prime Minister already in place. The establishment and institutionalization of an authentic and open DRM System, GIS based Disaster Information Management System will be strengthened. Collected information through this system will inform decision-making for risk reduction and preparedness in a more effective manner.

Finally, in order to strengthen cross-sectoral planning and coordination in the field of DRR, DRR and CRM focal points have been established in key agencies. These focal points work in a harmonized manner to ensure that Disaster and climate change risk reduction mainstreamed within respective ministries. Existing legal and policy framework on DRM:

- Constitution of Nepal

- Natural Calamity (Relief ) Act, 1982

- National Strategy on Disaster Risk Management, 2009

- National Disaster Response Framework, 2013

- Guidance Note on Disaster Preparedness and Response Planning, 2011

- National Strategic Action Plan for Search and Rescue, 2014

- District Disaster Preparedness and Response Plans

\section{Challenges}

More than two and half years after the devastating earthquakes that struck Nepal, the country is struggling to bounce back. Nearly $70 \%$ of the affected people still live in temporary shelters, and it is common to see damaged houses, temples without roofs, and earthquake debris lying around, even in the capital Kathmandu. The recovery is painfully slow, and many families who lost their loved ones continue to live in traumatic conditions. In the quakes' immediate aftermath, relief and rescue work began swiftly, with local volunteers working with the security forces and international aid workers. However, over the past two and half years the recovery effort has slowed to a crawl. Political bickering, a lack of accountability and poor management of funds have all hampered efforts to rebuild.

- One of the major challenges faced in the reconstruction process of Nepal is the absence of elected local government. Lack of government in local level was reflected in the major predisaster and post-disaster event, where it took months to reach the affected region and still no acceptable data is settled. In addition, the absence of an elected local government, top-down approach of governance has its own accountability deficit.

- Nepal's weak institutional framework for disaster management has been clearly proven to be ineffective and inefficient during and after the earthquake. In 2009, National Strategy for Disaster Risk Management (NSDRM) has been approved by MoHA, which basically stratifies the level of institutions into a central level, sub-national, district level and local 
Uprety: Gorkha Earthquake 2015 and Post Disaster...| 10

level. Though these different levels have been identified in the strategy paper, no significant implementation has been observed for pre-disaster preparedness

- Reconstruction is a very specialized work, needs a large number of technical manpower and expert. No I/NGOs in Nepal have or can manage such number of technical manpower as most of these I/NGOs have been working on awareness and social issues.

- Nepal is suffering from weak governance and corruption because of a decade-long political transition. Political instability, nepotism, clientelism, and lack of accountability prevail in the society and corruption is perceived to be a major concern.

- Existing social problems such as poverty, inequality, and unemployment before earthquake have increased the vulnerability of people and hindered people's interest to accelerate the reconstruction, especially to build a seismic resistant residential building.

- Lack of public awareness is another subcategory causing problems for people at disaster time and even during reconstruction. Lack of advanced knowledge and skills to respond and recover from a disaster and current level of education of public made them unable to play an active role in the process.

- In some cases, it takes over 1 day by road to travel from one end of the affected district to the other. The terrain makes transporting construction materials an impossible task in most of the area.

- The construction workforce, in general, lacked knowledge of earthquake-resistant technology because it has never been considered as an integral part of general engineering education in Nepal. The building construction mechanism is mostly vernacular, non-formal, incremental in nature, and dictated by the local availability of construction materials.

- Nepal has a long record of struggling to meet government expenditure targets even without the additional post-disaster pressures, for instance; it managed to spend only one-quarters of the capital expenditure budget for roads, dams and other infrastructures in 2015/16. The NRA has spent about 21 billion rupees for reconstruction so far against the budgetary allocation of 91 billion rupees for the 2015-2016 fiscal year.

- The most crucial factor in reducing a community's risk from an earthquake is the adoption and enforcement of up-to-date building codes and land use planning. The government of Nepal has decided to implement the Nepal building code in Kathmandu Valley in 2002. However, nearly 90 percent of homes in Kathmandu have not received the "construction conclusion" certificate, only because their homes do not meet building codes of Nepal.

- Land use planning after a mega earthquake can be an instrumental to reduce future seismic risk. It should be a significant part of the reconstruction. Reconstruction in large scale without land use planning will not be sustainable and long-lasting.

- NRA rules on grant distribution for landless peoples are delaying the rehabilitation and need to be more inclusive. Solving country's landlessness situation beforehand will obviate such issues.

- Resettlement of villages found critical by NRA surveys needed immediate NRA attention.

\section{Prospects}

Under the Government of Nepal, Nepal Reconstruction Authority (NRA) is responsible for leading and managing earthquake recovery and reconstruction initiative in Nepal. NRA provides the strategic guidance to identify and address the priorities for recovery and reconstruction, taking into accounts both urgent needs as well as long term plans. 


\section{1 | Journal of APF Command and Staff College}

Although the earthquake negatively influenced the country's economy, it opened the opportunity to create sustainable economic developments through proper education and training, media-based mass awareness, and coordinated actions in different parts of the society (including social workers, engineers, psychologists and educationists). Some opportunities can be listed as follows:

- The strong social bond among Nepalese citizens, irrespective of any sort of diversities, and that between international volunteers and Nepalese populations helped a lot for the rescue and recovery actions. The warm relation among the people is the treasure of the country and needs promotion to overcome the existing ethnical crisis.

- The proper channelization of the rescue and relief operations was made difficult due to limitations such as lack of infrastructure, like roads or airports, and experience.

- The proper channelization of the rescue and relief operations was made difficult due to limitations such as lack of infrastructure, like roads or airports, and experience. This can be put in consideration to manage any sort of disaster in future.

- There is a chance to change the crisis situation into an opportunity-to construct more sustainable infrastructures, using more local resources and traditional technologies and giving a more sustainable framework to the country's economic growth.

- Proper education, training and awareness are important elements. Proper training for all involved in the building process to erect safer buildings, in particular for masons, is a prime necessity to resist the future disaster.

- Strong political will and good governance are key issues to be considered, in order to tackle the disaster situation and to rebuild economy in sustainable way.

- Only good governance can help ensuring societal harmony and peace during situations of crisis

\section{Conclusion}

The Gorkha earthquake on April 25, 2015 has significantly affected the livelihood of people and overall economy in Nepal. The period of political transition, different institutions and systems are not in order of good performance in for seven decades and more. The key challenges of the reconstruction after 2015 earthquake are basically the inaccessibility, weak governance and corruption, knowledge gap, poverty and inequality, unemployment, large number of technical man power as construction workforce in general, lacked knowledge of earthquake-resistant technology, land use planning, resettlement of villages and so on. These challenges of reconstruction transpired after the 2015 earthquake has been holding back the pace of reconstruction. Short term and long term strategies are required for 'build back better' as opportunities of disaster. After a disaster, reconstruction often fails to adequately support community and economic development. The reconstruction process should be turn into alternative, more participatory approaches, such as people centered reconstruction. Too see this disaster as prospect for better development it is necessary to promote a decentralized and participatory approach to reconstruction, best use of local skills, institutions and resources, Include disaster risk assessments and decentralized disaster risk reduction into reconstruction processes to lessen vulnerability to future risks, promote the recovery of market systems that will build back local livelihoods and enable a more cost-effective and sustainable recovery.

\section{References}

Frontoso, M. G. (2017). Nepal: a Set of Challenges \& Opportunities. Journal of Build Change. Retrieved from http://www.buildchange.org/ 
Government of nepal reconstruction Authority. (2016). Post Disaster Recovery framework Retrived from file:PdRF, report

Kumar, N. (2016). Why Nepal Is Still in Rubble a Year after a Devastating Quake. Journal of Time Magazine. Retrieved from http://time.com/4305225/nepal-earthquake- anniversary-disaster/

Mahatara, B. (2017, December 12). Earthquake disaster: Reconstruction and recovery. The Himalaya Times. Retrieved from https://thehimalayantimes.com/ opinion/earthquake-disasterreconstruction-recovery/

National Position Paper for the AMCDRR.(2016). Disaster Risk Reduction in Nepal, Achievements, Challenges and Ways Forward.Retrieved from http://www.moha.gov. np/uploads/publicationFiles/9740_8e4c7c9f91b2cf707e43abc4ce6df2_1491503474_N.pdf

Nepal Development Research Institute. (2017). Post-Earthquake Activities of NDRI in Relief, Recovery and Reconstruction. Retrieved from Error! Hyperlink reference not valid.

Nepal's economic growth rate reached 7.5 percent. (2017, May 12). The Himalayan Post. Retrieved from https://thehimalayantimes.com/business/nepals-economic-growth-rate-reached-7-5percent-wb/

Sapkota, C. (2015). Accelerating Post-earthquake Reconstruction for Faster Recovery in Nepal. Blog Post. Retrieved from Error! Hyperlink reference not valid.

Sharma, K., \& KC, A. (2017, April 18). Reconstruction challenges in Nepal. Annapurna Post. Retrieved from http://www.annanote.com/news/6733

United Nations Office for Disaster Risk Reduction.(2015). Post-2015 framework for disaster risk reduction. Retrieved from https://www.unisdr.org/we/coordinate/hfa

Uprety, S., \&Panta, A. (2016). Road to Recovery: Summary of Post Disaster Recovery Framework. Journal of Health Research \& Social Development Forum. Retrieved from http://www.herd.org.np/blogs/13 